\title{
Anesthetic Drug Abuse by Anesthesiologists
}

\author{
Flavia Serebrenic Jungerman ${ }^{1}$, Hamer Nastasy Palhares Alves ${ }^{2}$, Maria José Carvalho Carmona, TSA ${ }^{3}$, \\ Nancy Brisola Conti ${ }^{4}$, André Malbergier ${ }^{5}$
}

\begin{abstract}
Summary: Jungerman FS, Palhares-Alves NH, Carmona MJC, Conti NB, Malbergier A - Anesthetic Drug Abuse by Anesthesiologists.
Background and objectives: Physicians has a slightly higher rate of psychoactive substance use when compared to the population in general. Anesthesiology is one of the most affected medicine specialties, especially due to overwork and easier access to drugs. This paper aims to carry out a literature review on the topic. Therefore, research was conducted by searching topic-related keywords on papers from the last 30 years available on MEDLINE.

Content: Despite the fact that alcohol abuse is the most common among anesthesiologists, the abuse of anesthetic agents causes more concern, due to its high dependence potential and consequences, which are often fatal. The most widely used drugs are opioids (fentanyl and sufentanil), propofol and inhalational anesthetics. Young professionals are the most affected. Among the consequences of drug abuse are workplace absence and even death. The return to operating rooms seems to increase the risk of relapse. In Europe and in the USA there are specialized treatment programs for the middle class, as well as preventive measures, such as strict control of drugs and identification of professionals at high risk of abuse. In Brazil, Anesthesiology is the second medicine specialty with most drug addicts, but the topic has not been much studied and there are few specialized programs in the field.
\end{abstract}

Conclusions: Substance abuse by anesthesiologists is an issue that needs to be discussed further, especially due to the possibility of severe consequences for professionals and patients.

Keywords: Absenteeism; Anesthesiology; Mortality; Occupational Diseases; Opioid Related Disorders; Physicians.

\section{INTRODUCTION}

The use of psychoactive substances is slightly higher among physicians if compared to the general population 1,2 .

Among physicians, anesthesiologists have more problems with psychoactive substance abuse, making it the most prevalent occupational risk in this group ${ }^{3}$.

There are many difficulties in identifying the problem, such as a fear of consequences and lack of technical and emotional skills to make the diagnosis ${ }^{4}$.

Physicians do not feel comfortable interfering in a colleague's personal life and they usually have little understanding of the issue ${ }^{5}$. This fact creates a 'silence conspiracy' involving family

Received from the Faculdade de Medicina da Universidade de São Paulo (USP), Brazil.

1. Psychologist; MSc in Chemical Dependence, University of London; PhD, Universidade Federal de São Paulo (UNIFESP); Member of the Interdisciplinary Study Group on Alcohol and Drug (GREA), Instituto de Psiquiatria, Hospital das Clínicas da Faculdade de Medicina da Universidade de São Paulo (HC-FM-USP)

2. PhD; Psychiatrist; Researcher; UNIAD-UNIFESP

3. Associate Professor, Subject of Anesthesiology, FM-USP; Anesthesia Division Director, Instituto Central, HC-FM-USP

4. Assistant Physician, Anesthesia Division, Instituto Central, HC-FM-USP; Preceptor of the Anesthesiology Medical Residency Program, FM-USP

5. Psychiatrist; Assistant Professor, Department of Psychiatry, FM-USP; Coordinator of GREA

Submitted on June 6, 2011.

Approved on August 29, 2011.

Correspondence to:

Dra. Flavia Serebrenic Jungerman

Rua Pascoal Vita, $n^{\circ}$ 342, 131

Pinheiros

05445000 - São Paulo, SP, Brazil

Email: fla.de@uol.com.br members, colleagues and the doctor ${ }^{6}$. When the substance user is someone who has a higher rank, others fear punishment when tackling the problem. On the other hand, family members recognize the problem but are afraid to reveal it in the workplace due to financial and occupational consequences. The belief that substance dependence is a choice and not a disease can also divert attention from the problem ${ }^{7}$.

Substance abuse is one of the major causes of stress among anesthesiologists' chiefs of service, in addition to issues related to attendance, accreditation, budget, failing at the university and social security audit ${ }^{8}$. Related mortality is significant ${ }^{9}$, as well as resulting occupational difficulties.

Such a situation requires a thorough debate. This paper aims to provide a review of the studies on psychoactive substance abuse among anesthesiologists, especially those concerning anesthetic agents, considered as special concern and a source of increased deaths among these professionals.

\section{METHOD}

In order to evaluate the issue of substance use among anesthesiologists in the last 30 years (1980-2010), a bibliographical survey was carried out on the MEDLINE database. The keywords used were opioid, physicians, substance abuse, Anesthesiologists and occupational mortality, and the language filters were English and Portuguese. During the search by keywords, 60 studies in English and Portuguese were selected from the database. 


\section{RESULTS}

\section{Epidemiology}

The prevalence of impaired physicians due to substance use is $10 \%$ to $12 \%$. This prevalence is higher than in the general population for alcohol and two controlled substances: opioids and tranquilizers ${ }^{10,11}$. According to estimates, $14 \%$ of doctors become dependent on drug or alcohol during their professional life, and the highest incidence occurs during the first five years after graduation ${ }^{12}$.

Alcohol is the substance most widely used by physicians, and it is responsible for almost half of the cases mentioned. However, attention should be directed to the fact that doctors are more vulnerable to abuse of controlled substance than the population in general. In a study with 904 physicians monitored for drug abuse, more than a half of them were from five specialties: Family Medicine (20\%), Internal Medicine (13.1\%), Anesthesia (10.9\%), Emergency Medicine (7.1\%) and Psychiatry $(6.9 \%)$. The anesthesiologists are more susceptible to abuse of very potent opioids, especially fentanyl and sufentanil 9 .

\section{The anesthesiologist}

due to the difficulty in identifying cases of substance abuse among anesthesiologists, the true prevalence is unknown ${ }^{13}$. However, it is believed to be at least as prevalent as for the general population ${ }^{14}$.

In 1983, Anesthesiology and Anesthesia Nursing residency programs were studied for 10 years, and the prevalence of dependence was $1 \%{ }^{15}$, a rate similar to another study published that same year ${ }^{16}$.

The illicit use of opioids and other drugs by anesthesiologists is three times higher than in other specialties ${ }^{17}$.

Despite thorough debate on the subject and the use of preventive actions over the last years, the incidence does not seem to change. In 1997, 133 residency programs were followed. The survey showed a response rate of $93 \%$, and dependence prevalence of $1.6 \%$ among residents and of $1 \%$ among hired physicians, although $47 \%$ of these programs had improved their preventive interventions focusing on substance abuse ${ }^{18}$.

The prevalence of anesthetic agent abuse, in particular fentanyl, is thought to be high among Anesthesiology residents. It is estimated at $1.6 \% 19$.

In a study carried out from 1991 to 2001 in the USA, including several residency Anesthesiology programs, with a response rate of $66 \%, 80 \%$ of the programs reported experience with impaired residents and $19 \%$ reported at least one fatality 7,20 . Out of the 111 respondent programs, $16 \%$ periodically included a screening test for substance abuse during the selection process and 15\% required urine testing prior to applying for a medical residency program.
The majority of impaired residents attempted to return to residency after treatment. Only $46 \%$ of the impaired residents completed training.

Despite preventive strategies, the mortality rate still causes concern: studies report $10 \%{ }^{21}$ and $19 \%$ rates of fatal cases ${ }^{7,20}$.

A study including 304 Anesthesiology departments, carried out in Ireland and in the United Kingdom 22 from 1990 to 1999, revealed cases of substance abuse in $39 \%$ of the departments. It also verified that, every month, one anesthesiologist was dismissed for drug dependence. Some studies show similarly high incidences in Australia and New Zealand ${ }^{23}$. Not only physicians are at risk; nurse anesthetists are as well ${ }^{24}$.

\section{Types of psychoactive controlled substances}

The drug most used by anesthetists is alcohol (50\%), followed by opioids $(33 \%)$, stimulants $(8 \%)$ or other substances $(9 \%)^{25}$.

Among the anesthetic agents most used by anesthesiologists are the opioids ${ }^{26}$, but there has been increased concern with propofol ${ }^{27}$ and inhalational anesthetics ${ }^{28}$.

\section{Propofol}

An American survey conducted via email and telephone calls to the chairs of the Anesthesia Departments to detect the prevalence of propofol abuse in 126 Anesthesiology residency programs revealed that $18 \%$ of the programs reported one or more cases of propofol abuse over the last decade ${ }^{27}$. This figure represents a fivefold increase if compared to the previous survey. Among 25 individuals abusing propofol, seven died, which corresponds to a rate of $28 \%$. Taking only the residents into account $(n=16)$, there were six fatal cases, which increased the mortality rate to $38 \%$.

One of the possible reasons for the use of propofol is related to its great dependence potential. Research has shown that subanesthetic doses are sufficient to increase the dopamine concentration in the nucleus accumbens, which is a region that is strictly associated to the brain reward system 29 . Thus, propofol would produce a great reinforcement potential, which would explain its frequent use ${ }^{30,31}$.

\section{Inhalation agents}

In a survey that included 106 Anesthesiology departments, Wilson et al. ${ }^{28}$ noticed that 23 of the departments had one or more individuals abusing inhalation anesthetics, totalling 31 addicts.

\section{Opioids}

Anesthesiologists tend to abuse more opioids, such as fentanyl and sufentanil ${ }^{32}$. This abuse is usually associated with other psychiatric comorbidities. A review performed in 1991 
found $57 \%$ prevalence of personality disorder among drug users ${ }^{33}$. This data suggest that self-medication can be possible motivation for future illicit use ${ }^{32}$.

In a program for substance-dependent physicians in the USA, 904 physicians were observed for five years (1995-2001) and 104 of them were anesthesiologists. According to research, compared to other physicians, anesthesiologists entered treatment more frequently for abuse of opioids rather than for abuse of alcohol or other drugs. The anesthesiologists were more strictly monitored and more frequently tested for drugs. Their outcomes were similar to those of other physicians; there was no difference regarding treatment completion, disciplinary rate, return to practice, mortality rate, and no evidence in their records of patient harm after relapse ${ }^{34}$.

\section{Why anesthesiologists do abuse controlled substances?}

Several factors related to anesthesiologist's professional life contribute to drug use. Easy access to drugs, lonesome and stressful activities, excessive hours of work and the possible relation with other psychiatric diseases are some of them ${ }^{1,2}$. The high tendency towards self-medication seems to be a risk factor for experimenting with psychoactive substances ${ }^{35}$.

In addition, anesthesiologists have almost free access to large quantities of highly addictive drugs, which makes it easier to divert particularly small quantities of these agents for personal use ${ }^{12,20,32,36}$.

Exposure in the workplace has been proposed to explain the high dependence rate among anesthesiologists. Exposure to the air in the workplace would sensitize the brain reward system. This factor would arouse curiosity and increase the tendency to experiment with and abuse substances ${ }^{37-39}$. Exposure could be either through aerosol particles in the air of surgical centers or through particles exhaled by patients ${ }^{30,40}$.

\section{Consequences of controlled substance abuse by anesthesiologists}

The mortality rate for middle class is below $1 \%$ from the period of 1979 to 1995, except for suicide rate, which is higher. Anesthesiologists have a higher death risk due to suicide (rate ratio [RR] 1.45; confidence interval [Cl] of $95 \%$ 1.07-21.97), i.e. anesthesiologists have 1.45 more chance to commit suicide than other physicians, 2.79 more chance to die from drug-related causes (RR 2.79, Cl 95\% 1.87-4.15), 1.53 more chance to die from other external causes (RR 1.53, Cl 95\% 1.05-2.22) and 1.39 more chance to die from vascular brain diseases (RR 1.39, Cl 95\% 1.08-21.79).

Anesthesiologists present more risks of death and suicide related to drugs in the first five years after graduation, but the rate decreases with time. It is believed that mortality rate is higher among younger physicians, as they use more potent anesthetics during residency ${ }^{12}$.
The consequences of the use and abuse of substances by anesthesiologists are many and not only are they related to the physician's occupation, but also to their social lives ${ }^{25}$. The moral burden is still remarkable besides being counterproductive. DuPont et al. ${ }^{25}$ reported that $17 \%$ of the interviewees in a physician assistance program were arrested for offense due to alcohol or drug use and $9 \%$ were punished. Thirty nine percent had entered dependence treatment previously and $14 \%$ had already received a disciplinary action by the employer before treatment.

According to the survey conducted by Wischmeyer et al. ${ }^{27}$, among the 16 residents dependent on propofol, six died, three abandoned Medicine and five entered other specialties. Only two residents remained in the field of Anesthesiology.

According to the study of Wilson et al. ${ }^{28}$ with 106 interviewees, $31(29 \%)$ were addicts, and $48 \%$ were sent for rehabilitation. The mortality rate was $26 \%$ (eight cases), and five of them were among residents. This means a mortality rate of $36 \%(5 / 14)$ for inhalation substances. Seven out of 31 interviewees $(22 \%)$ completed the program and five entered another specialty.

In a survey conducted in the Anesthesiology residences in the USA from 1991 to 2001, most residents attempted to re-enter clinical practice of Anesthesiology after treatment 20. Only $46 \%$ were successful in completing the anesthesiology residency. Forty percent of the residents who underwent treatment and returned to medical training entered into another specialty. The mortality rate for Anesthesiology residents was $9 \%$. Long-term follow-up was reported for $93 \%$ of all treated residents. Of these, $56 \%$ were successful in some other medicine specialty.

It is generally believed that anesthesiologists who are dependent on opioids, propofol or inhaled anesthetics deserve special consideration, as the mortality rate among theses physicians is high 27,28 .

Regarding the occupational issue, the return to the workplace of an anesthesiologist that has had problems with controlled substance abuse is controversial. While some studies suggest a careful re-entry to clinical practice, operating rooms included ${ }^{26}$, others recommend against it, as relapse is a high risk when attempting to return to work ${ }^{36}$.

In a study, five residents identified as being addicted to a controlled substance were removed from their residency program and offered treatment. The treatment involved a 12month monitoring program in an anesthesia simulation environment. The program offered them a flexible-hour job as well as a salary, like what regular residents are offered. Of the five residents participating in the program, three completed their residency and their five-year monitoring contract. Although the study had only five participants, it concluded that the return to Anesthesiology practice can be a realistic goal for addicted physicians. However, reintroduction must be undertaken in a slow, gradual and monitored fashion. The authors emphasize the relevance of taking into account the possibility of relapse and the risks of a quick reintroduction to work ${ }^{26}$.

On the other hand, several studies show evidence against the reintroduction of anesthesiologists to operating rooms. In many cases, opioid dependent physicians may relapse when 
returning to workplace and this can result in death 20 . Therefore, it is necessary to further discuss the possibility of redirecting the treated anesthesiologists to other medicine specialties in order to reduce risks and increase the possibilities of having a successful professional life 20 .

Some authors do not recommend the return to operating room activities due to the risk of relapse, which is increased by easy access to drugs ${ }^{36}$. Their recommendation is based on a study with nurse anesthetists with a relapse tax of almost $100 \%$ after having returned to surgical practice ${ }^{41}$.

Wilson et al. ${ }^{28}$ share this view and state that reintroduction to the Anesthesiology work environment contradicts the process of rehabilitation, as the addict is again exposed to stimuli that may lead to relapse. That is why it is extremely important to monitor the addict's return to the workplace.

After the publication of the paper of Berge et al. ${ }^{36}$, many letters were sent questioning their radical attitude ('one strike, you are out') to relapse and after a thorough literature review, Oreskovich et al. ${ }^{42}$ concluded that the return of an impaired physician to the operating room is too risky, unless they are submitted to highly-monitored PHP programs (Physicians' Health Program) and that these programs are audited (as the programs differ from one place to the other).

In a later study, Berge et al. ${ }^{6}$ suggested a more general approach to investigate, intervene and watch the pshysicians who may be abusing substances. The authors highlight that psychiatric comorbity and family history of substance abuse increase the risk of relapse. This was shown in a study with anesthesiologists who relapsed ${ }^{43}$.

\section{Treatment}

In 1993, a study reviewed the issue of addiction among anesthesiologists (Opioid Addiction in Anesthesiology) ${ }^{44}$ and suggested treatment and prevention strategies.

Some studies suggest that once addiction is diagnosed, the physician should be directed to rehabilitation centers and, if possible, specifically dedicated to physicians only ${ }^{45}$. Most treatments are influenced by the Minnesota model, which includes detoxification, monitored withdrawal, intensive education, participation in mutual help groups and psychotherapy ${ }^{46}$.

After having completed treatment in rehabilitation centers, anesthesiologists are usually directed to residential treatment for a period of two months or up to one year. The objective at this first stage is to prepare the patient for a long-term withdrawal period and for rehabilitation. Ideally, the patient is sent to a halfway house (i.e., to an assisted living facility, outside rehabilitation centers within society, but with constant help of qualified personnel), or directly to society. The patient is expected not to relapse, despite the proximity to drugs in the work environment. The patient should continue treatment in ambulatory care centers in order to be constantly monitored 26 .

The PHP (Physicians' Health Program), which is a health program that provides support for all medicine specialties, was created in the U.S.A. The program is aimed at both protecting the general public and the lives and careers of impai- red physicians. The program lasts five years and is focused on total withdrawal. These programs reveal a rehabilitation tax of $70 \%$ to $96 \%$, and admission to the program is mandatory for the patient's re-entry to work $17,39,43,47,48$. During the first three months, the physician stays at an inpatient setting. During the rest of the year, the physician receives outpatient treatment. The families get involved in the treatment process and are advised on how to deal with drug dependence. After the first year, physicians return to work and are randomly tested for drugs and alcohol. They are also monitored and helped. Physicians who relapse (who abuse substance or who do not attend self-help groups) are not excluded from the program, but receive a more intensive treatment. The Program's five objectives were chosen based on evidence. The five objectives are:

1. Contingency management aspects of PHP care management. The physicians' attitudes towards treatment (presence or absence) will be positively or negatively reinforced via a therapeutic contract;

2. Frequently random drug and alcohol screens;

3. Attendance at self-help groups to achieve total withdrawal from drugs.

4. Continued treatment for at least five years ;

5. Focus on the physician's rehabilitation and quality of life.

There are two interesting facts about this study: the minority of the physicians involved (5\%) was on medication (they used naltrexone, which is an opioid antagonist that reduces or extinguishes intoxication in case of relapse), and although the physicians who entered treatment voluntarily had better results, those who entered involuntarily were also benefited from the treatment.

The survey that evaluated 904 physicians involved in this program in 16 American states verified that $78 \%$ of the participants were tested negative for alcohol and drugs during the five-year monitoring, i.e., the results showed withdrawal. Seventy-two percent were practicing Medicine 25 .

Some studies reveal a high rehabilitation rate among physicians, between $74 \%$ and $90 \%$, a rate comparable to the recovery of airline pilots $17,43,49-52$. Some of these studies report that physicians re-enter clinical practice. Thus they suggest an appropriate rehabilitation model and support so that physicians return to work.

In 1986, the Alcohol and Drug Foundation of Australia set forth an initiative to decrease substance abuse among anesthesiologists by promoting programs to educate physicians about the risks and consequences of abuse ${ }^{53}$.

As substance abuse is usually associated with other comorbities, especially psychiatric ones, it is essential to identify and treat them ${ }^{32}$. It is believed that mutual help groups are helpful during abuse recovery, as well as for occupational reintegration. 
Anesthesiologists suffering from substance abuse should be directed to treatment administered by qualified personnel ${ }^{38}$. Everybody should be aware so as to recognize and help their colleagues.

In 2002, the São Paulo Regional Medical Council (CREMESP) and the Paulista Medical School created in Brazil a service called Rede de apoio aos médicos (the Physician's Support Network) to help the physicians of the state of São Paulo. The project is aimed at reducing the physician's inability due to mental disorders and chemical dependence. It is a comprehensive program that includes drug therapy, psychotherapy and other kinds of therapies ${ }^{54}$. Brazilian studies also suggest that anesthesiologists are the most affected physicians (about $15 \%$ of the physicians treated are anesthesiologists, and they only represent $3 \%$ of the doctors). Unlike the American and Canadian models, which have legal-based programs, it is a volunteer-based program, so accepting treatment is more difficult.

Orientation during the medicine course and the residency program to the risks of getting involved with psychoactive substances, as well as the development of orientation, tutorial and treatment services may play an important role in therapy and early detection ${ }^{55-57 .}$

Impaired physicians may not look for help for fear of professional consequences. That is why all physicians should help and encourage their colleagues to look for the appropriate treatment. Specific services for physicians have been highly recommended $1,58,59$.

Despite recent advances in chemical dependence treatment, there is still a lack of efficient approaches and rehabilitation protocols among anesthetists ${ }^{32}$. Most of Anesthesiology services have already tackled this kind of problem, and $80 \%$ of the American medicine residency programs reported opioid dependence cases. In order to change this scenario, it is essential to make an early diagnosis, to recognize psychiatric comorbity cases ${ }^{43}$ and to mantain long-term treatment.

\section{Preventive measures for substance use control}

Concerning specifically Anesthesiology, the literature reports that one of the strategies used to deal with the indiscriminate use of anesthetics in the workplace is to control the substances used in surgical procedures or sedation for diagnosis/ anesthesia. In the survey conducted by Wischmeyer with anesthesia training programs ${ }^{27}, 71 \%$ regulated opoids but not propofol. In an online study with chairpersons of anesthesia groups in the United States, Wilson et al. ${ }^{28}$ concluded that the majority of the departments (93\%) do not have any pharmacy control of inhalational anesthetics.

Spain developed programs in order to control access to these substances ${ }^{60}$.

\section{Use of controlled substances in Brazil}

In Brazil, the illicit use of anesthetic substances, especially among anesthesiologists, has led to problems related to the physician's professional life, such as the need to stay away from work or change anesthesiology activity and, mainly, for several cases of interruption of clinical practice and deaths. Alves et al. ${ }^{1}$ reviewed medical records of 198 physicians attending outpatient treatment for harmful substance use or dependence, including exclusively alcohol (34.3\%) and exclusively drugs (28.3\%) or both (36.8\%). The most used drugs were cocaine, benzodiazepines, cannabis, opioids, amphetamines and solvents. Among residents (79.3\%), the most involved specialties were Internal Medicine (25.2\%), Anesthesiology $(12.6 \%)$ and Surgery (12.6\%). The index of self-medication was considered extremely high $(65.1 \%)$, which suggests the use of drugs to relieve psychic pain or work overload. The authors emphasize the importance of an educational process encouraging the orientation and direction of patients to treatment. They also suggest the creation of specific services for trial and case detection, long-term support and monitoring, as well as control mechanisms and a careful re-entry process.

Based on the aforementioned study, a physician care network was created. However, this issue has not been much discussed in Brazil. There are no specific studies about the drug abuse in the field of Anesthesiology and there are also no appropriate programs. But as there are always new cases of addiction among anesthesiologists, the decisions are made individually, with no debate on general measures to be taken by physicians.

\section{DISCUSSION}

Substance abuse seems to be more prevalent among physicians than among the general population. Alcohol is the most abused substance. Compared to other specialties, anesthesiologists are most vulnerable to controlled substance abuse, basically because of occupational issues (excessive work hours and easy access to drugs). The most abused substances are opioids (fentanyl, in particular), propofol and inhalation anesthetics. These are highly addictive and potentially lethal drugs.

The dependent physician must be diagnosed and removed from medical practice, as well as submitted to a long-term detoxification and rehabilitation program and ample reintegration to society. This involves self-help group meeting attendance, family support and regular test monitoring.

The return of anesthesiologists to operating rooms may increase the risk of relapse.

In Brazil, despite the ample understanding of the issue concerning substance abuse by anesthesiologists, there are no well-established treatment and prevention programs. It is therefore necessary to invest in education, therapies and specific personnel to approach the problem. 
5. Farber NJ, Gilibert SG, Aboff BM, Collier VU, Weiner J, Boyer EG Physicians willingness to report impaired colleagues. Soc Sci Med, 2005;61(8):1772-1775.

6. Berge KH, Seppala MD, Schipper AM - Chemical dependency and the physician. Mayo Clin Proc, 2009;84(7):625-631.

7. Talbott GD - The impaired physician and intervention: a key to recovery. J Fla Med Assoc, 1982;69(9):793-797.

8. De Oliveira GS Jr, Ahmad S, Stock MC et al. - High incidence of burnout in academic chairpersons of anesthesiology: should we be taking better care of our leaders? Anesthesiology, 2011;114(1):181-193.

9. Collins GB, McAllister MS, Jensen M, Gooden TA - Chemical dependency treatment outcomes of residents in anesthesiology: results of a survey. Anesth Analg, 2005;101(5):1457-1462.

10. Hughes $P$ - Can we improve on how we select medical students? J R Soc Med, 2002;95(1):18-22.

11. McLellan AT, Skipper GS, Campbell M, DuPont RL - Five year outcomes in a cohort study of physicians treated for substance use disorders in the United States. BMJ Clinical research ed., 2008;337:a2038.

12. Alexander BH, Checkoway H, Nagahama SI, Domino KB - Causespecific mortality risks of anesthesiologists. Anesthesiology, 2000;93(4):922-930.

13. Brewster JM - Prevalence of alcohol and other drug problems among physicians. JAMA, 1986;255(14):1913-1920.

14. Krizek TJ - The impaired surgical resident. Surg Clin North Am, 2004;84(6):1587-1604.

15. Ward CF, Ward GC, Saidman LJ - Drug abuse in anesthesia training programs. A survey: 1970 through 1980. JAMA, 1983;250(7):922925.

16. Gravenstein JS, Kory WP, Marks RG - Drug abuse by anesthesia personnel. Anesth Analg, 1983;62(5):467-472.

17. Talbott GD, Wright $C$ - Chemical dependency in health care professionals. Occup Med, 1987;2(3):581-591.

18. Booth JV, Grossman D, Moore J et al. - Substance abuse among physicians: a survey of academic anesthesiology programs. Anesth Analg, 2002;95(4):1024-1030.

19. Levine MR, Rennie WP - Pre-employment urine drug testing of hospital employees: future questions and review of current literature. Occup Environ Med, 2004;61(4):318-324.

20. Collins GB, McAllister MS, Jensen M, Gooden TA - Chemical dependency treatment outcomes of residents in anesthesiology: results of a survey. Anesth Analg, 2005;101(5):1457-1462.

21. Spiegelman WG, Saunders L, Mazze RI - Addiction and anesthesiology. Anesthesiology, 1984;60(4):335-341.

22. Berry CB, Crome IB, Plant M, Plant M - Substance misuse amongst anaesthetists in the United Kingdom and Ireland. The results of a study commissioned by the Association of Anaesthetists of Great Britain and Ireland. Anaesthesia, 2000;55(10):946-952.

23. Weeks AM, Buckland MR, Morgan EB, Myles PS - Chemical dependence in anaesthetic registrars in Australia and New Zealand. Anaesth Int Care, 1993;21(2):151-155.

24. Bell DM, McDonough JP, Ellison JS, Fitzhugh EC - Controlled drug misuse by Certified Registered Nurse Anesthetists. AANA Journal, 1999;67(2):133-140.

\section{REFERÊNCIAS/REFERENCES}

1. Alves HN, Surjan JC, Nogueira-Martins LA, Marques AC, Ramos SP, Laranjeira RR - Clinical and demographical aspects of alcohol and drug dependent physicians. Rev Assoc Med Bras, 2005;51(3):139143.

2. Robb N-University acknowledges special risks, introduces drug program for anesthetists. Cmaj, 1995;153(4):449-452.

3. Tetzalff $\mathrm{J}-$ Chemical dependency and anesthesiology. [conference presentation] Cleveland, Ohio 2009.

4. McGlynn EA, Asch SM, Adams $J$ et al. - The quality of health care delivered to adults in the United States. New Eng J Med, 2003;348(26):2635-2645.

25. DuPont RL, McLellan AT, White WL, Merlo LJ, Gold MS - Setting the standard for recovery: Physicians Health Programs. J Subst Abuse Treat, 2009;36(2):159-171.

26. Bryson EO, Levine A - One approach to the return to residency for anesthesia residents recovering from opioid addiction. J Clin Anesth, 2008;20(5):397-400.

27. Wischmeyer PE, Johnson BR, Wilson JE et al. - A survey of propofol abuse in academic anesthesia programs. Anesth Analg, 2007;105(4):1066-1071.

28. Wilson JE, Kiselanova N, Stevens Q et al. - A survey of inhalational anaesthetic abuse in anaesthesia training programmes. Anaesthesia, 2008;63(6):616-620.

29. Pain L, Gobaille $S$, Schleef $C$, Aunis D, Oberling $P$ - In vivo dopamine measurements in the nucleus accumbens after nonanesthetic and anesthetic doses of propofol in rats. Anesth Analg, 2002;95(4):915-919. 
30. McAuliffe PF, Gold MS, Bajpai L et al. - Second-hand exposure to aerosolized intravenous anesthetics propofol and fentanyl may cause sensitization and subsequent opiate addiction among anesthesiologists and surgeons. Med Hypoth, 2006;66(5):874-882.

31. Zacny JP, Lichtor JL, Coalson DW et al. - Subjective and psychomotor effects of subanesthetic doses of propofol in healthy volunteers. Anesthesiology, 1992;76(5):696-702.

32. Bryson EO, Silverstein $\mathrm{JH}$ - Addiction and substance abuse in anesthesiology. Anesthesiology, 2008;109(5):905-917.

33. Nace EP, Davis CW, Gaspari JP - Axis II comorbidity in substance abusers. Am J Psych, 1991;148(1):118-120.

34. Skipper GE, Campbell MD, Dupont RL - Anesthesiologists with substance use disorders: a 5-year outcome study from 16 state physician health programs. Anesth Analg, 2009;109(3):891-896.

35. Hughes PH, Brandenburg N, Baldwin DC Jr. et al. - Prevalence of substance use among US physicians. JAMA, 1992;267(17):23332239.

36. Berge KH, Seppala MD, Lanier WL - The anesthesiology communitys approach to opioid- and anesthetic-abusing personnel: time to change course. Anesthesiology, 2008;109(5):762-764.

37. Fitzsimons MG, Baker KH, Lowenstein E, Zapol WM - Random drug testing to reduce the incidence of addiction in anesthesia residents: preliminary results from one program. Anesth Analg, 2008;107(2):630635.

38. Gold MS, Byars JA, Frost-Pineda K - Occupational exposure and addictions for physicians: case studies and theoretical implications. Psychiatr Clin North Am, 2004;27(4):745-753.

39. Gold MS, Frost-Pineda K, Melker RJ - Physician suicide and drug abuse. The American journal of psychiatry. [Comment Letter]. 2005;162(7):1390.

40. Gold MS, Melker RJ, Dennis DM et al. - Fentanyl abuse and dependence: further evidence for second hand exposure hypothesis. J Add Dis, 2006;25(1):15-21.

41. Marienau, ME and KHB - Personal verbal communication. Rochester, Minnesota, October 2007.

42. Oreskovich MR, Caldeiro RM - Anesthesiologists recovering from chemical dependency: can they safely return to the operating room? Mayo Clinic Proceedings, 2009;84(7):576-580.

43. Domino KB, Hornbein TF, Polissar NL et al - Risk factors for relapse in health care professionals with substance use disorders. JAMA, 2005;293(12):1453-1460.

44. Silverstein $\mathrm{JH}$, Silva DA, Iberti TJ - Opioid addiction in anesthesiology. Anesthesiology, 1993;79(2):354-375.

45. Hankes $L$, Bissel $L-$ Health professionals. In: Lowinson and Millman, editors. - SUbstance abuse: a comprehensive textbook. Baltimore: Lippincott/Williams \&Wilkins; 1992. pp. 897-908.

46. Rounsaville BJ, Carroll KM - Individual psychotherapy for drug abusers, In: Lowinson, Ruiz and Langrod editors. Substance abuse: a Comprehensive textbook. New York, 1992. pp. 496-508.

47. Gastfriend DR - Physician substance abuse and recovery: what does it mean for physicians and everyone else? JAMA, 2005;293(12):15131515.

48. Smith PC, Smith JD - Treatment outcomes of impaired physicians in Oklahoma. J Okla State Med Assoc, 1991;84(12):599-603.

49. Kintz $P$, Villain $M$, Dumestre V, Cirimele V - Evidence of addiction by anesthesiologists as documented by hair analysis. Forensic Sci Int, 2005;153(1):81-84.

50. Gallegos KV, Norton M - Characterization of Georgias Impaired Physicians Program treatment population: data and statistics. J Med Assoc $\mathrm{Ga}, 1984 ; 73(11): 755-758$.

51. Kliner DJ, Spicer J, Barnett $P$ - Treatment outcome of alcoholic physicians. J Stud Alcohol, 1980;41(11):1217-1220.

52. Skutar $\mathrm{C}-$ Physicians Recovery Network targets attitudes about impairment. Mich Med, 1990;89(12):30-32.

53. Gladstone W, Webster IW, Rotem A - An initiative for teaching about alcohol and other drugs in Australian medical schools. Med J Aust, 1987;147(7):339-341.
54. Palhares-Alves HN, Laranjeira R, Nogueira-Martins LA - A pioneering experience in Brazil: the creation of a support network for alcohol and drug dependent physicians. A preliminary report. Rev Bras Psiquiatr, 2007;29(3):258-261.

55. Marcolino JA, Vieira JE, Piccinini Filho L, Mathias LA - Mentoring during residency in anesthesiology: the Irmandade da Santa Casa de Misericordia, São Paulo Program. Rev Bras Anestesiol, 2004;54(3):438447.

56. Fagnani Neto R, Obara CS, Macedo PC, Citero VA, Nogueira-Martins LA - Clinical and demographic profile of users of a mental health system for medical residents and other health professionals undergoing training at the Universidade Federal de São Paulo. São Paulo Med J, 2004;122(4):152-157.

57. Kerr-Correa FGA, Bassit AZ, Boccutto NMVF - Uso de alcool e drogas por estudantes de medicina da Unesp. Rev Bras Psiquiatr, 1999;21(2):95-100.

58. Newbury-Birch D, Walshaw D, Kamali F - Drink and drugs: from medical students to doctors. Drug Alcohol Depende, 2001;64(3):265-270.

59. Baldisseri MR - Impaired healthcare professional. Crit Care Med, 2007;35(2Suppl):S106-S116.

60. Sanz Yaguez F, Lopez Corbalan JC - Abuse of psychoactive drugs among health professionals. Rev Esp Anestesiol Reanim, 1999;46(8):354-358. 